\title{
Effects of Genotype and Isolate on Expression of Dollar Spot in Seashore Paspalum
}

\author{
Clinton J. Steketee \\ Institute of Plant Breeding, Genetics, and Genomics, University of Georgia, \\ 111 Riverbend Road, Athens, GA 30602
}

\author{
Alfredo D. Martinez-Espinoza \\ Department of Plant Pathology, University of Georgia, 1109 Experiment \\ Street, Griffin, GA 30223
}

Karen R. Harris-Shultz

USDA-ARS, 115 Coastal Way, Tifton, GA 31793

Gerald M. Henry

Department of Crop and Soil Sciences, University of Georgia, 3111 Miller Plant Sciences, Athens, GA 30602

\author{
Paul L. Raymer ${ }^{1}$ \\ Institute of Plant Breeding, Genetics, and Genomics and Department of Crop \\ and Soil Sciences, University of Georgia, 1109 Experiment Street, Griffin, GA \\ 30223
}

Additional index words. turfgrass, Sclerotinia homoeocarpa, Paspalum vaginatum, host plant resistance

\begin{abstract}
Seashore paspalum (Paspalum vaginatum Swartz) is a warm-season turfgrass species primarily used on golf courses and athletic fields, and is often impacted by the disease dollar spot caused by Sclerotinia homoeocarpa F.T. Bennett. Dollar spot is the most common and economically important turfgrass disease in North America, and current management of this disease relies heavily on frequent fungicide applications. An alternate management strategy is host plant resistance, but a better understanding of the interactions between pathogen isolates and the host species is needed to effectively incorporate this resistance into elite seashore paspalum genotypes. The goal of this study was to gather host plant/isolate response data that could be used to develop an effective and efficient screening protocol for resistance to this important disease. Five genotypes of seashore paspalum ('Aloha', 'SeaIsle 2000', 'SeaIsle 1', 'SeaIsle Supreme', and 05-1743) varying in dollar spot resistance were inoculated with five isolates of $\boldsymbol{S}$. homoeocarpa in repeated field studies during 2012 and 2013. Isolates used were from three warm-season and one cool-season turfgrass species. Inoculated plots were evaluated visually and using digital image analysis (DIA) for disease development over time and for number and area of infection centers at two rating dates each year. Statistical differences among the seashore paspalum genotypes and inoculation/isolate treatments were detected for area under the disease progress curve (AUDPC) values, number of infection centers, and infection center area. A significant interaction between seashore paspalum genotype and $S$. homoeocarpa isolate effects was not observed, indicating that host plant resistance genes are likely not isolate specific. Using this information, breeders should be able to use one highly virulent $S$. homoeocarpa isolate to screen for host plant resistance in seashore paspalum.
\end{abstract}

Seashore paspalum ( $P$. vaginatum $)$ is a warm-season, perennial turfgrass (Morton, 1973) that is used primarily as a fine-bladed turfgrass in recreational areas. This littoral, $\mathrm{C}_{4}$ species is typically found in tropical to warm temperate regions (Chapman and Peat, 1992). Several biotic stresses affect seashore paspalum including nematodes, insects, and pathogens. In particular, plant diseases can be a major problem for turfgrass practitioners

Received for publication 30 Apr. 2015. Accepted for publication 2 Oct. 2015.

${ }^{1}$ Corresponding author. E-mail: praymer@uga.edu. managing seashore paspalum. Dollar spot, caused by $S$. homoeocarpa (Bennett, 1937), is one of the most important fungal diseases that affects turfgrass, and can cause extensive damage to highly maintained turfgrasses such as those found on golf course fairways and putting greens. Dollar spot can reduce turf quality and playability of fine-textured paspalum. This disease is a widespread problem throughout the world, and nearly all cultivated turfgrass species can be a host for this pathogen (Allen et al., 2005).

Turfgrass cultural practices, such as proper nitrogen fertility and irrigation, are commonly used to reduce dollar spot symptoms in a turfgrass sward. The removal of guttation fluids with dew whips or the use of lightweight rollers can also reduce disease severity (Giordano et al., 2012). Chemical and biological fungicides are also tools used to manage dollar spot (Walsh et al., 1999). However, facultative saprophytes like $S$. homoeocarpa can develop acquired pesticide resistance to site-specific fungicides. Benzimidazoles, demethylation inhibitors, dicarboximides, and nitriles are common classes of fungicides that have been effective for management of dollar spot. Boscalid (Emerald $^{\circledR}$; BASF, Research Triangle Park, NC), a carboximide, can also be used to control $S$. homoeocarpa, and is one of the few fungicide classes to which $S$. homoeocarpa has not developed resistance (Allen et al., 2005).

Genetically controlled host plant resistance is the most promising of the management strategies for control of dollar spot (Bonos et al., 2003), and some resistant or partially resistant cultivars are available for many common turfgrass species. Screening by Raymer et al. (2008) showed substantial differences in $S$. homoeocarpa resistance among eight standard seashore paspalum varieties. Paspalum vaginatum germplasm with disease resistance can be used as parents in a breeding program to develop cultivars with improved dollar spot resistance. Development of seashore paspalum cultivars that exhibit resistance to $S$. homoeocarpa would greatly reduce the cost and environmental impact of fungicide applications and other management practices.

Much of the research on genetic host resistance has been conducted on the coolseason turfgrass, creeping bentgrass (Agrostis stolonifera L.). Cultivars of creeping bentgrass differ in their response to $S$. homoeocarpa; however, no cultivar is completely resistant to the pathogen (Morris, 2005; Vincelli et al., 1997). Bonos et al. (2003) found that a population of creeping bentgrass clones from a dollar spot resistant by dollar spot susceptible cross formed a continuous distribution of dollar spot severity phenotypes, indicating that resistance is likely quantitative with two to five effective factors associated with resistance to the pathogen. High, narrow-sense heritability was also observed for this trait (Bonos, 2006). Further research indicated that a few genes were likely interacting in an additive manner to confer dollar spot resistance in creeping bentgrass (Bonos, 2011). Quantitative trait loci (QTLs) associated with dollar spot resistance have also been identified for creeping bentgrass, and could help facilitate markerassisted selection in breeding programs (Chakraborty et al., 2006a; Honig et al., 2014). Chromosomal regions associated with dollar spot resistance have been identified in colonial bentgrass (Agrostis capillaris L.) as well (Rotter et al., 2011). Molecular markers linked to dollar spot resistance gene(s) have not been developed in seashore paspalum, but if available, they could be used to transfer the resistance into elite cultivars using marker-assisted selection. 
Artificially inoculating turfgrasses with the $S$. homoeocarpa pathogen can be an effective way to screen for resistance or susceptibility. Preparation of inoculum typically involves autoclaving flasks containing seed and then placing small pieces of $S$. homoeocarpa colonized potato dextrose agar (PDA) media inside the flask to infect sterile seeds with the pathogen. This procedure has been accomplished using seeds of kentucky bluegrass (Poa pratensis L.) (Bonos et al., 2003; Chakraborty et al., 2006a; Oliveira et al., 2010); wheat (Flor et al., 2013); and equal mixtures of wheat, barley, and oats (Goodman and Burpee, 1991). These inoculum sources have been created using both single and combinations of $S$. homoeocarpa isolates.

It is unclear if screening with multiple isolates is necessary to identify seashore paspalum genotypes with broad-spectrum dollar spot resistance. The objectives of this study were to 1) evaluate the disease expression of seashore paspalum genotypes inoculated with $S$. homoeocarpa isolates collected from cool- and warm-season turfgrass species, 2) identify which of these isolates are most effective to use for resistance screening, and 3) determine if significant genotype by isolate interactions occurred which would indicate a need for screening with multiple $S$. homoeocarpa isolates. This experiment is necessary to determine how to best screen for resistance to this important disease.

\section{Materials and Methods}

Plant material. Five seashore paspalum genotypes with variation in dollar spot resistance were evaluated, and were selected for this study based on their response to $S$. homoeocarpa from observations as well as published and unpublished data. These genotypes were geographically diverse in their origin (Table 1) and included 'Aloha', 'SeaIsle 2000', 'SeaIsle 1', 'SeaIsle Supreme', and 05-1743, an experimental line in The University of Georgia (UGA) paspalum breeding program. These five genotypes were established in field plots at the UGA Griffin Campus, Griffin, GA, in 2007 as part of a variety trial. The seashore paspalum genotypes were arranged randomly, and there were three replications of each genotype with the exception of SeaIsle Supreme, which had two. Before conducting the experiment, the plot was irrigated three times weekly, fertilized monthly at a rate of $49 \mathrm{~kg} \mathrm{~N} / \mathrm{ha}$, and mowed three times weekly at $1.6 \mathrm{~cm}$ with a reel mower. During the first week after artificially inoculating the plots, no mowing occurred to prevent spread of the inoculum, and no additional fertilizer was applied during the duration of the experiment.

Sclerotinia homoeocarpa isolates and inoculation method. Five $S$. homoeocarpa isolates that were collected from a variety of warm- and cool-season turfgrass species were evaluated. These were general seashore paspalum (P1), seashore paspalum 50149 (P2), zoysiagrass (Zoysia japonica Steudel) 3 (ZY), common bermudagrass (Cynodon dactylon $\mathrm{L}$.) 1 (BG), and a creeping bentgrass isolate $(\mathrm{CB})$. All isolates were obtained from the collection maintained by Dr. MartinezEspinoza at the UGA Griffin Campus, Griffin, GA. Isolates were maintained on an equal mixture of wheat, barley, and oat seed at $5^{\circ} \mathrm{C}$. The final inoculum used to artificially inoculate the plant material was also grown on an equal mixture of wheat, barley, and oat seed. This inoculum was prepared by first filling $1000 \mathrm{~mL}$ Erlenmeyer flasks with $\approx 200 \mathrm{~mL}$ by volume of the seed mixture, adding $250 \mathrm{~mL}$ of water, and allowing it to soak overnight. The next day, water was drained from the grain mixture, and the flasks were covered and autoclaved. The grain mixture was autoclaved a second time the following day.

Potato dextrose agar (Difco, Becton, Dickinson and Company, Franklin Lakes, NJ) infested with the $S$. homoeocarpa isolates was sliced into $2-\mathrm{cm}^{2}$ squares using a scalpel under sterile conditions. Four squares of colonized PDA of a particular isolate were then placed in each flask containing the autoclaved grain mixture. The flasks were shaken once daily to promote even spread of the $S$. homoeocarpa pathogen. After 2 weeks, $50 \mathrm{~mL}$ by volume of the appropriate inoculum mixture was spread by hand onto the subplots with treatments requiring $S$. homoeocarpa inoculation. Inoculations of the plant material occurred on 18 Oct. 2012 and again on 22 Aug. 2013. Plots continued to receive irrigation three times weekly after inoculation.

Experimental design. The experiment was a split-plot design, with five seashore paspalum genotypes representing the main plots $(1.5 \times 3.0 \mathrm{~m})$, and eight treatments as the subplots $(0.75 \times 0.75 \mathrm{~m})$. Emerald $^{\circledR}$ fungicide, used to control native inoculum, was applied to six of the eight subplots $28 \mathrm{~d}$ before initiating the study at the manufacturer's recommended rate for dollar spot management. The eight treatments included the five $S$. homoeocarpa isolates as well as three control treatments. The treatments were boscalid control (BC), which was sprayed with

Table 1. Geographic origin and dollar spot resistance of five seashore paspalum genotypes.

\begin{tabular}{lll}
\hline Genotype & \multicolumn{1}{c}{ Origin } & Dollar spot resistance \\
\hline $05-1743$ & University of Georgia Experimental Line & Poor/Moderate \\
Aloha & Hawaii, United States & Poor \\
SeaIsle 1 & Argentina & Moderate/Excellent \\
SeaIsle 2000 & Florida, United States & Excellent \\
SeaIsle Supreme & South Carolina, United States & Poor/Moderate \\
\hline
\end{tabular}

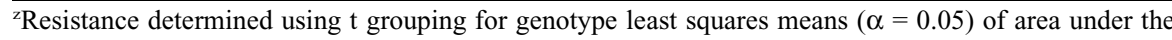
disease progress curve (AUDPC) values over both rating years. Geographic origin adapted from Duncan and Carrow (2000).
Emerald $^{\circledR}$ fungicide; native control (NC), which was not sprayed with the Emerald $^{\circledR}$ fungicide; artificial inoculation with P1, P2, $\mathrm{ZY}, \mathrm{BG}$, or $\mathrm{CB}$ isolates applied to subplots treated with fungicide; and $\mathrm{NC}+\mathrm{P} 1$, which was inoculated with $\mathrm{P} 1 S$. homoeocarpa isolate on a subplot not sprayed with Emerald ${ }^{\circledR}$.

Rating and DIA. Both visual ratings and DIA were used to rate dollar spot symptoms on the subplots. Ratings were taken for visual percent disease with $0 \%$ showing no dollar spot symptoms and $100 \%$ being completely symptomatic. Ratings were taken twice weekly for $\approx 5$ weeks after artificial inoculation (WAI), because this coincided with maximum disease pressure or recovery. Images were captured using a Canon PowerShot G6 digital camera (Canon USA, Melville, NY) in JPEG (joint photographic experts group, or “.jpg”) format with an image resolution of $3072 \times$ 2304 pixels. An aperture of $\mathrm{f} / 5.6$ was selected to provide proper exposure. The camera was mounted on a NexGen ${ }^{\circledR}$ (NexGen Turf Research, Albany, OR) light box equipped with four incandescent light bulbs (900 lumens, EcoSmart, Home Depot, Atlanta, GA) within the box to provide a consistent, constant light source. Digital images were captured once weekly, then downloaded in order of plot number, and saved for later processing and analysis.

Digital images were analyzed and processed using Assess version 2.2, a software program from APS Press (American Phytopathological Society, St. Paul, MN) that specializes in DIA. Before using the program, all images were carefully examined to ensure consistent quality and were cropped to eliminate pixels of the light box structure when needed. The analysis was emulated after Horvath and Vargas (2005) using a leaf hue threshold of 31-191 and lesion threshold of 31-107. Percent disease severity (total lesion pixels/total pixels) was calculated using Assess version 2.2, and then recorded and stored in a Microsoft Excel (Microsoft, Redmond, WA) worksheet for each image.

Number of infection centers and infection center area were also collected for two rating dates, 1 and 15 Nov. 2012 and 5 and 20 Sept. 2013. Area without holes, length, and roundness were selected in the options menu of the Assess software. The leaf hue threshold was set for 31-191, while the lesion hue threshold was set for 31-101. This change in lesion hue was selected, because it is the default setting for infection center analysis. The count feature of this software was used to monitor infection center objects between 1000 and 50,000 pixels. Infection center and infection center area without holes were then recorded and stored in a Microsoft Excel worksheet. This process was repeated for each image collected for the four image collection dates. Infection center area was averaged for all lesions counted for each picture to conduct statistical analysis more efficiently.

Disease progress curves were generated from both the visual- and Assess-generated ratings. The AUDPC was then calculated for 
both rating methods. The equation for AUDPC was adapted from Shaner and Finney (1977) and each disease progress curve was calculated by:

$$
\sum_{i}^{n-1}\left(\frac{y_{i}+y_{i+1}}{2}\right)\left(t_{i+1}-t\right)
$$

where $n$ is the number of assessment times, $y$ is disease measure (percent disease), and $t$ is the time in days.

Statistical analysis. All data collected were subjected to an analysis of variance (ANOVA). Percent disease was evaluated for eight treatments within five seashore paspalum genotypes using two rating methods, and was collected over 2 years at one location. Analysis was conducted using error partitioning appropriate to a split-plot analysis in the generalized linear mixed model procedure for AUDPC using SAS version 9.3 (SAS Institute Inc., Cary, NC). Seashore paspalum genotypes, treatments, rating method, and their respective interactions were used to construct a model for AUDPC. Replication and year effects were not included in the model statement and were treated as random effects.

Analysis for infection centers was conducted as a general linear model with seashore paspalum genotypes, treatments, year, and rating date used to construct a model for the number of infection centers. A model using the same effects was constructed for average infection center area, and both were analyzed using SAS version 9.3. In this case, rating date and year were treated as fixed effects. Analysis was done in this manner due to significant year and rating date effects when analyzed as a combined years' data set.

A linear regression analysis to compare visual and DIA techniques was computed using the correlation procedure in SAS version 9.3. Correlations of rating method by year, and combined rating methods were obtained.

\section{Results}

Lack of genotype by isolate interaction based on AUDPC values. The combined ANOVA using data from both 2012 and 2013 and the two rating methods showed there were statistical differences in seashore paspalum genotypes $(\mathrm{F}=5.33 ; P=0.0042)$ and treatments $(\mathrm{F}=37.86 ; P \leq 0.0001)$ (Table 2). This is an indication that genotypes differed in host resistance, and that individual isolates caused different amounts of disease severity. However, the interaction between genotypes and isolates was not significant (Table 2), meaning that while disease severity varied among genotypes, a particular $S$. homoeocarpa isolate caused a relatively similar amount of symptoms regardless of the genotype it infected and host plant-resistance genes are likely not isolate specific. There were no statistical differences $(\mathrm{F}=0.16 ; P=$ 0.6930 ) in visual vs. Assess version 2.2 AUDPC values calculated from percent disease ratings over time (Table 2).

Paspalum genotype differences based on AUDPC values for both years. Higher
AUDPC values indicate greater disease severity and less host plant resistance. Aloha had significantly more disease symptoms than both SeaIsle 1 and SeaIsle 2000. Also, SeaIsle 2000 had significantly less disease than SeaIsle Supreme and 05-1743 (Fig. 1).

Isolate and control treatment differences based on AUDPC values. Higher AUDPC

Table 2. Summary of analysis of variance for effects of seashore paspalum genotypes, treatments, rating methods, and interactions based on area under the disease progress curve (AUDPC) values tested over 2 years.

\begin{tabular}{lcrr}
\hline Effect & Degrees of freedom & F value & $P>\mathrm{F}$ \\
\hline Genotype (G) & 4 & 5.33 & 0.0042 \\
Treatment (T) & 7 & 37.86 & $<0.0001$ \\
Rating method (RM) & 1 & 0.16 & 0.6930 \\
G $\times$ T & 28 & 0.95 & 0.5390 \\
G $\times$ RM & 4 & 1.41 & 0.2308 \\
T $\times$ RM & 7 & 11.4 & $<0.0001$ \\
\hline
\end{tabular}

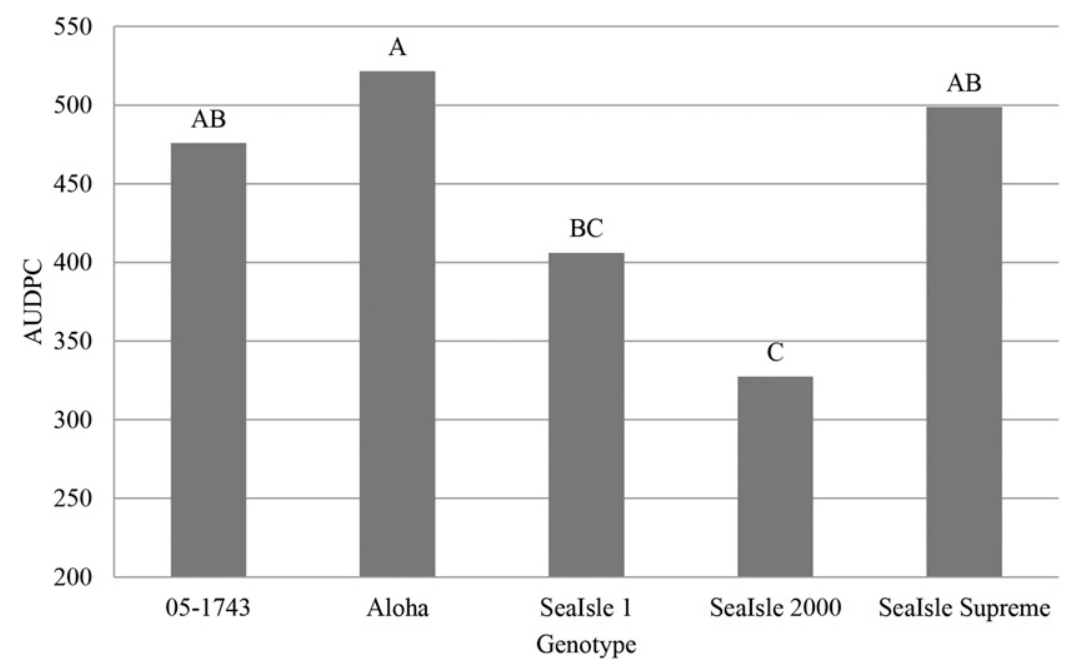

Fig. 1. Average area under the disease progress curve (AUDPC) values for five seashore paspalum genotypes averaged over the eight treatments tested over 2 years. Genotypes with the same letter above the bar are not statistically different according to pairwise $t$ tests at the $\alpha=0.05$ level.

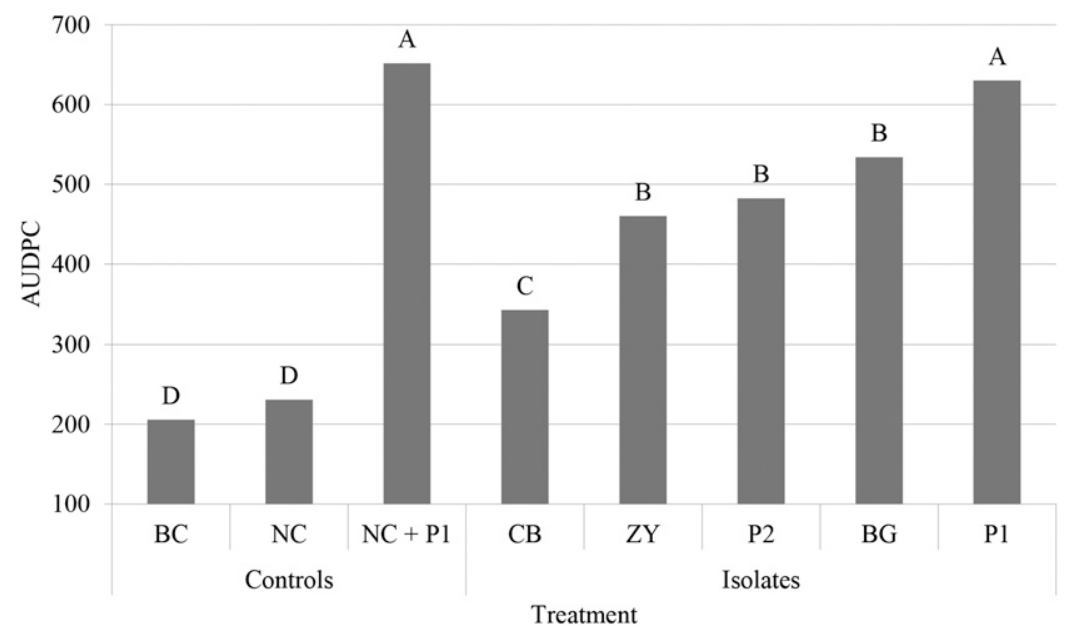

Fig. 2. Average area under the disease progress curve (AUDPC) values for eight treatments tested over 2 years. Treatments: $\mathrm{BC}=$ boscalid control; $\mathrm{NC}=$ native control; $\mathrm{NC}+\mathrm{P} 1=$ native control plus general seashore paspalum isolate; $\mathrm{CB}=$ creeping bentgrass isolate; $\mathrm{ZY}=$ zoysiagrass isolate; $\mathrm{P} 2$ = seashore paspalum 50149 isolate; $\mathrm{BG}=$ common bermudagrass isolate; $\mathrm{P} 1$ = general seashore paspalum isolate. Treatments with the same letter above the bar are not statistically different according to pairwise $t$ tests at the $\alpha=0.05$ level. 
treatments, and had the lowest AUDPC mean among the isolates tested. The $\mathrm{NC}$ and $\mathrm{BC}$ control treatments had the lowest AUDPC means for the experiment and were in the statistical group with lowest disease pressure, as expected (Fig. 2). The lack of difference in the fungicide control (BC) and the native inoculum treatment (NC) also confirmed that low levels of native $S$. homoeocarpa inoculum were present at the testing site.

Correlation between rating methods. The 2012 Assess version 2.2 AUDPC values by 2012 visual AUDPC had an $r$ coefficient value of 0.74 , while 2013 Assess version 2.2 AUDPC by 2013 visual AUDPC values had an $r$ coefficient value of 0.94 . Assess version 2.2 and visual AUDPC values were then combined for both years using percent dollar spot disease AUDPC values (not the infection center or infection center area data) from the generalized linear mixed model

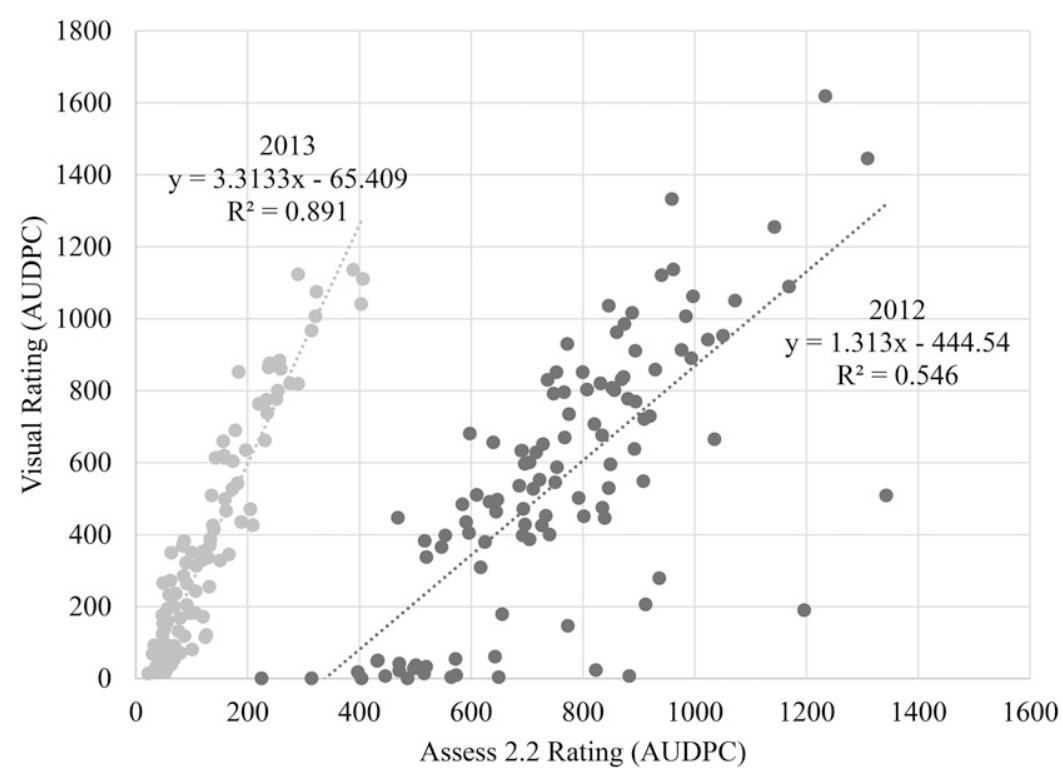

Fig. 3. Scatterplot of Assess 2.2 vs. visual ratings based on area under the disease progress curve (AUDPC) values in 2012 and 2013. Using linear regression, Assess 2.2 AUDPC (2012) by visual AUDPC (2012) had an $r$ coefficient value of 0.74, while Assess 2.2 AUDPC (2013) by visual AUDPC (2013) had an $r$ coefficient value of 0.94 . Combining AUDPC values from both repetitions (years) of the experiment showed the overall correlation between the two rating methods was $r=0.79$. infection centers. Genotype and treatment effects were both significant $(\alpha=0.05)$ according to ANOVA for each rating date separately (data not shown).

Infection center data used to measure disease severity of seashore paspalum genotypes were collected 2 and 4 weeks after initial inoculation occurred in both 2012 and 2013. Overall, the average number of infection centers counted for all genotypes and isolate treatments was 85.9 at $2 \mathrm{WAI}$ in $2012,174.3$ at $4 \mathrm{WAI}$ in 2012, 6.1 at $2 \mathrm{WAI}$ in 2013, and 32.6 at $4 \mathrm{WAI}$ in 2013. Aloha and SeaIsle Supreme had a significantly higher number of infection centers than the other three genotypes tested at 2 WAI in 2012 (Fig. 4). At 4 WAI in 2012, Aloha (197 average infection centers) was in the statistical group with the highest number of infection centers. SeaIsle 2000 (151.7 average infection centers) had statistically fewer infection centers than Aloha and 05-1743 at 4 WAI in 2012 (Fig. 4). At 2 WAI in 2013, SeaIsle 2000 had significantly fewer average number of infection centers than 05-1743. SeaIsle 1 and SeaIsle 2000 had statistically fewer average number of infection centers than the other three seashore paspalum genotypes tested.

The number of infection centers at $2 \mathrm{WAI}$ in 2012 was highest for the BG, NC + P1, P1, and $\mathrm{ZY}$ treatments (Fig. 5). The $\mathrm{BC}$ and $\mathrm{NC}$ control treatments had the fewest number of infection centers, and were statistically different from all other treatments with the exception of $\mathrm{CB}$ (Fig. 5). At 4 WAI in 2012, the analysis showed much different statistical groupings, compared with 2 WAI. The $\mathrm{CB}$ and $\mathrm{NC}$ treatments were in the statistical group containing the highest number of infection centers, whereas BG, P1, and $\mathrm{NC}+\mathrm{P} 1$ were in the group containing the fewest number of $S$. homoeocarpa infection centers (Fig. 5). The $\mathrm{NC}+\mathrm{P} 1$ and $\mathrm{P} 1$ treatments were once again in the statistical grouping with the greatest average number of infection centers at $2 \mathrm{WAI}$ in 2013. These two treatments also had the greatest average number of infection centers at $4 \mathrm{WAI}$ in 2013.

Infection center area. The ANOVA showed that rating dates $(\mathrm{F}=336.64 ; P \leq 0.0001)$,

Table 3. Summary of analysis of variance for rating date, seashore paspalum genotypes, treatments, and respective interactions based on analysis of number of infection centers for two rating dates in 2012 ( 1 and 15 Nov.), number of infection centers for two rating dates in 2013 (5 and 20 Sept.), average infection center area for two rating dates in 2012 ( 1 and 15 Nov.), and average infection center area for two rating dates in 2013 (5 and 20 Sept.).

\begin{tabular}{|c|c|c|c|c|c|c|c|}
\hline \multicolumn{4}{|c|}{2012 Number of infection centers } & \multicolumn{4}{|c|}{2013 Number of infection centers } \\
\hline Effect & Degrees of freedom & F value & $P>\mathrm{F}$ & Effect & Degrees of freedom & $\mathrm{F}$ value & $P>\mathrm{F}$ \\
\hline Genotype (G) & 4 & 8.16 & $<0.0001$ & Genotype $(\mathrm{G})$ & 4 & 8.80 & $<0.0001$ \\
\hline $\mathrm{G} \times \mathrm{T}$ & 28 & 2.29 & 0.0008 & $\mathrm{G} \times \mathrm{T}$ & 28 & 1.35 & 0.1311 \\
\hline $\mathrm{RD} \times \mathrm{G} \times \mathrm{T}$ & 39 & 3.57 & $<0.0001$ & $\mathrm{RD} \times \mathrm{G} \times \mathrm{T}$ & 39 & 1.80 & 0.0068 \\
\hline \multicolumn{4}{|c|}{2012 Infection center area } & \multicolumn{4}{|c|}{2013 Infection center area } \\
\hline Effect & Degrees of freedom & F value & $P>\mathrm{F}$ & Effect & Degrees of freedom & F Value & $P>\mathrm{F}$ \\
\hline Treatment $(\mathrm{T})$ & 7 & 28.77 & $<0.0001$ & Treatment $(\mathrm{T})$ & 7 & 4.37 & 0.0002 \\
\hline $\mathrm{G} \times \mathrm{T}$ & 28 & 1.47 & 0.0737 & $\mathrm{G} \times \mathrm{T}$ & 28 & 0.83 & 0.7162 \\
\hline $\mathrm{RD} \times \mathrm{G} \times \mathrm{T}$ & 39 & 3.26 & $<0.0001$ & $\mathrm{RD} \times \mathrm{G} \times \mathrm{T}$ & 39 & 0.53 & 0.9886 \\
\hline
\end{tabular}




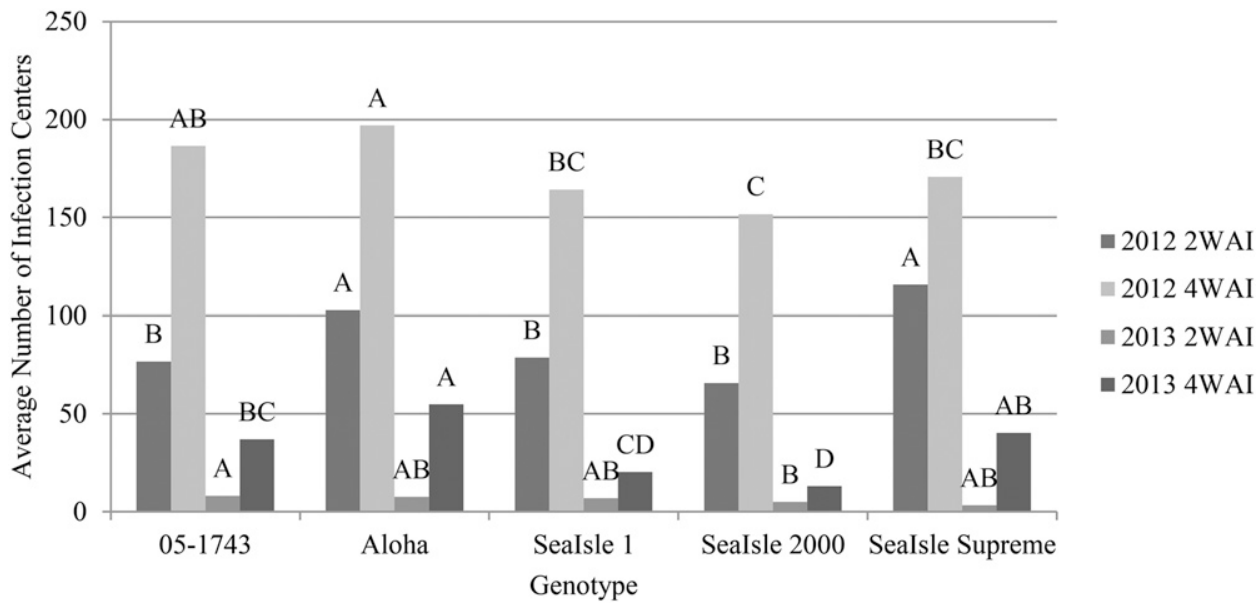

Fig. 4. Average number of infection centers for five seashore paspalum genotypes averaged over the eight treatments tested at two different rating dates in 2 years. $2 \mathrm{WAI}=2$ weeks after artificial inoculation and $4 \mathrm{WAI}=4$ weeks after artificial inoculation. Genotypes with the same letter above the same rating date bar are not statistically different according to pairwise $t$ tests at the $\alpha=0.05$ level. Genotypic comparisons are made within a single rating date, not across rating dates.

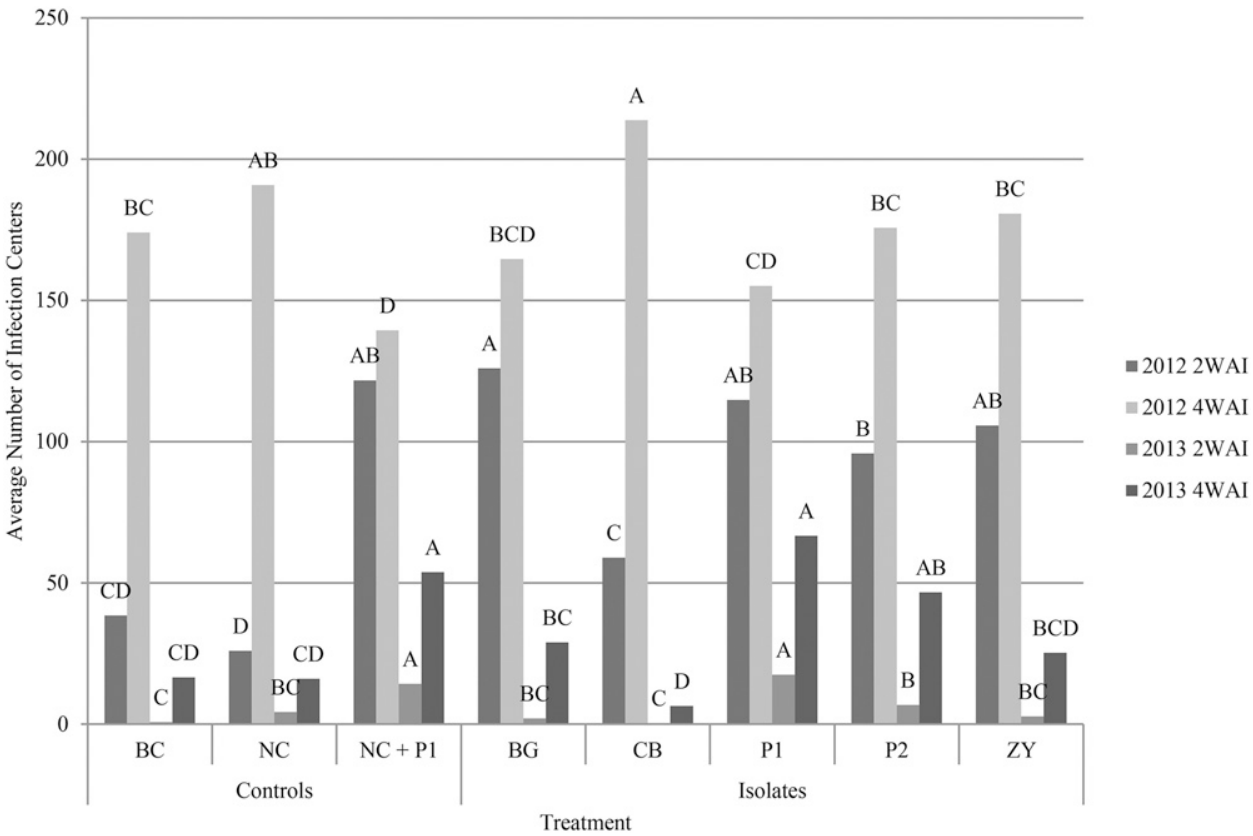

Fig. 5. Average number of infection centers for eight treatments at two different rating dates in two years. $2 \mathrm{WAI}=2$ weeks after artificial inoculation, and $4 \mathrm{WAI}=$ 4 weeks after artificial inoculation. Treatments: $\mathrm{BC}=$ boscalid control; $\mathrm{NC}=$ native control; $\mathrm{NC}+\mathrm{P} 1=$ native control plus general seashore paspalum isolate; $\mathrm{CB}=$ creeping bentgrass isolate $\mathrm{ZY}=$ zoysiagrass isolate $\mathrm{P} 2=$ seashore paspalum 50149 isolate $; \mathrm{BG}=$ common bermudagrass isolate; $\mathrm{P} 1=$ general seashore paspalum isolate. Treatments with the same letter above the rating date bar are not statistically different according to pairwise $t$ tests at the $\alpha=0.05$ level. Comparisons are made between treatments within a single rating date, not across rating dates.

seashore paspalum genotypes $(\mathrm{F}=8.21 ; P \leq$ $0.0001)$, and treatments $(\mathrm{F}=28.77 ; P \leq$ $0.0001)$ for average infection center area analysis were statistically different in 2012. Similar results were observed for data collected in 2013 with rating date $(\mathrm{F}=33.82 ; P \leq 0.0001)$, seashore paspalum genotypes $(\mathrm{F}=3.06 ; P=$ $0.0186)$, and treatments $(\mathrm{F}=4.37 ; P=0.0002)$ showing significant differences (Table 3 ). This is an indication that genotypes differed in their average infection center area, and that the isolates caused different average $S$. homoeocarpa infection center areas. Genotype and treatment were both significant $(\alpha=0.05)$ according to ANOVA for each rating date separately (data not shown).
Average infection center area data for seashore paspalum genotypes were collected 2 and 4 WAI occurred in both 2012 and 2013. Overall, the average area of infection centers (in pixels) for all genotypes and isolate treatments was 2455 for 2 WAI in 2012, 5778 for 4 WAI in 2012, 1369 for 2 WAI in 2013, and 2199 for $4 \mathrm{WAI}$ in 2013. At $2 \mathrm{WAI}$ in 2012, SeaIsle Supreme had the largest average infection center area (3283 pixels) and was statistically different from the other genotypes tested (Fig. 6). 05-1743 (2130 pixels) and SeaIsle 2000 (2050 pixels) had the smallest average infection center area, and were significantly different from SeaIsle Supreme and Aloha. At 4 WAI in 2012,
SeaIsle Supreme was in the statistical group with the highest average $S$. homoeocarpa infection center area. 05-1743 and SeaIsle 2000 were also in the group with the smallest infection center area again, and were statistically different from SeaIsle Supreme and SeaIsle 1 (Fig. 6). There were no significant differences among the genotypes tested at 2 WAI in 2013. At 4 WAI in 2013, 05-1743 and Aloha were in the statistical grouping with the greatest average infection center area.

At 2 WAI in 2012, the NC + P1 (3312 pixels) and $\mathrm{P} 1$ (3196 pixels) treatments were in the statistical group with the largest average $S$. homoeocarpa infection center area (Fig. 7). The CB (1850 pixels) and BC 


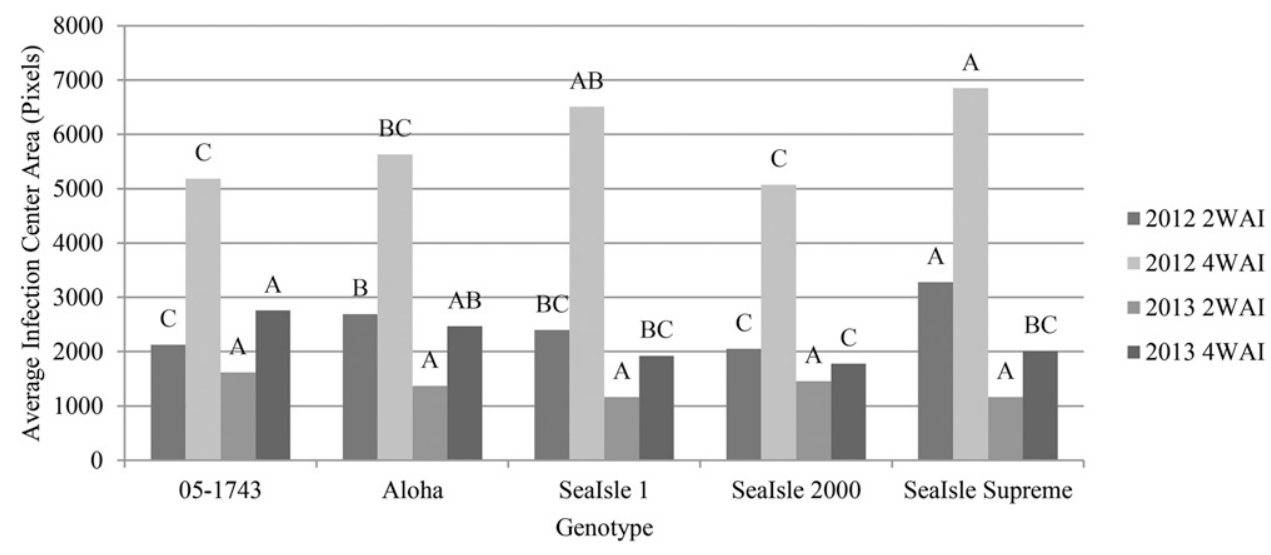

Fig. 6. Average infection center area for five seashore paspalum genotypes averaged overall isolate treatments for two different rating dates in 2 years. $2 \mathrm{WAI}=2$ weeks after artificial inoculation and $4 \mathrm{WAI}=4$ weeks after artificial inoculation. Genotypes with the same letter above the same rating date bar are not statistically different according to pairwise $t$ tests at the $\alpha=0.05$ level. Comparisons are made within a single rating date, not across rating dates.

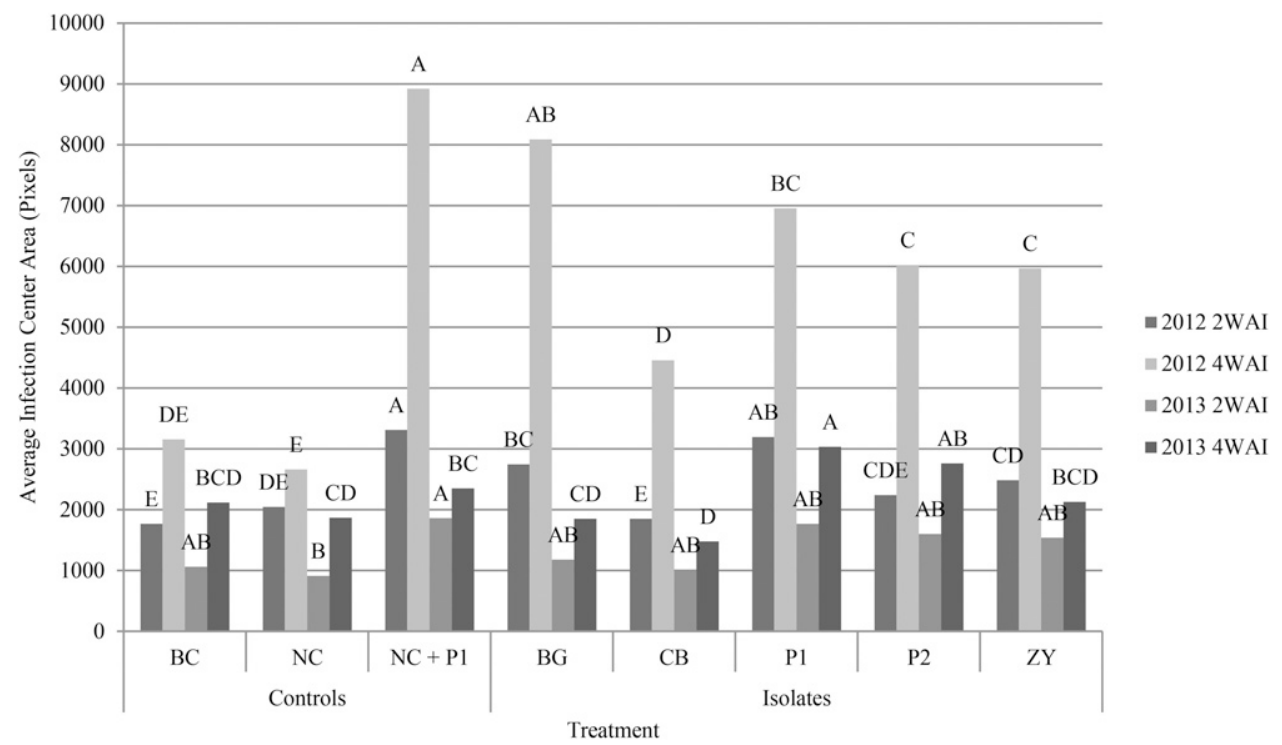

Fig. 7. Average infection center area for eight treatments tested for two different rating dates in 2 years. $2 \mathrm{WAI}=2$ weeks after artificial inoculation and $4 \mathrm{WAI}=4$ weeks after artificial inoculation. Treatments: $\mathrm{BC}=$ boscalid control; $\mathrm{NC}=$ native control; $\mathrm{NC}+\mathrm{P} 1=$ native control plus general seashore paspalum isolate; $\mathrm{CB}=$ creeping bentgrass isolate $\mathrm{ZY}=$ zoysiagrass isolate $\mathrm{P} 2=$ seashore paspalum 50149 isolate; $\mathrm{BG}=$ common bermudagrass isolate; $\mathrm{P} 1=$ general seashore paspalum isolate. Treatments with the same letter above the same rating date bar are not statistically different according to pairwise $t$ tests at the $\alpha=0.05$ level. Comparisons are made between treatments within a single rating date, not across rating dates.

(1768 pixels) treatments had the smallest infection center area, and were significantly different from all treatments except $\mathrm{P} 2$ and NC. At 4 WAI in 2012, the NC + P1 and BG treatments produced the highest average $S$. homoeocarpa infection center area. P1 was also large, but not statistically different from the $\mathrm{BG}$ treatment. The $\mathrm{BC}$ and $\mathrm{NC}$ treatments had the smallest average infection center area, and were statistically different from all other treatments except CB (Fig. 7). In 2013 at $2 \mathrm{WAI}$, the $\mathrm{NC}+\mathrm{P} 1$ treatment had significantly larger average infection center area than the NC treatment. At 4 WAI in 2013, the $\mathrm{P} 1$ and $\mathrm{P} 2$ treatments had the greatest average infection center area.

\section{Discussion}

There were statistical differences in AUDPC among the seashore paspalum genotypes and treatments tested (Table 2). An objective of this study was to determine if interactions were occurring between seashore paspalum genotypes and the $S$. homoeocarpa isolates; there was not a significant interaction (Table 2). The lack of significant genotype by isolate interaction suggests that seashore paspalum $S$. homoeocarpa resistance genes are not isolate specific. Our results indicate that seashore paspalum breeders can use a single, highly virulent $S$. homoeocarpa isolate to select for host plant resistance to this pathogen, and make the process of screening for resistance much faster and efficient.

Several previously published studies observed little genetic diversity among $S$. homoeocarpa isolates. Chakraborty et al. (2006b) tested $18 \mathrm{~S}$. homoeocarpa isolates, representing 10 vegetative compatibility groups (VCGs), by inoculating 12 creeping bentgrass cultivars. Evaluations of disease severity showed significant differences among bentgrass cultivars with respect to dollar spot response; however, data from pathogenicity tests showed there were no race-specific interactions. Powell and Vargas (2001) conducted a similar study with 1300 isolates in six VCGs. Sequences from the internal transcribed spacer 1 of all the VCGs were the same, indicating these VCGs represent a single $S$. homoeocarpa species. These studies showed that turfgrass breeders should be able to select for dollar spot resistance in creeping bentgrass with the use of a single virulent isolate of $S$. homoeocarpa. Our findings indicate this is true for seashore paspalum as well. However, more recent publications have indicated that populations of $S$. homoeocarpa are very diverse and contain more VCGs than previously reported (Putman et al., 2015). According to Liberti 
et al. (2012), two distinct morphological types of $S$. homoeocarpa have been identified, forming distinct common and Floridian types. However, the Floridian type forms distinct VCGs and produces different symptoms than all other isolates documented in the literature. The common type produces a watersoaked lesion, and the Floridian type causes strong leaf blade yellowing. Viji et al. (2004) also suggested a difference in VCGs in isolates collected from Florida.

Correlations were high when comparing the two different rating methods for each repetition (2012 and 2013), and overall for both years (Fig. 3). This finding provides support for the use of DIA as a reliable technique for field disease studies. Horvath and Vargas (2005) compared the use of DIA vs. foci counts for measuring response to $S$. homoeocarpa infection on a mixed sward of creeping bentgrass and annual bluegrass ( $\mathrm{Poa}$ annua L.) and found that the AUDPC curves generated for these two rating methods were not significantly different. The results of our experiment agree with their findings. Once trained on how to use available software programs, this type of analysis can be more costeffective, does not require personnel trained in rating disease plots, and also removes the possibility of bias in collecting data.

The data collected for number of $S$. homoeocarpa infection centers and average infection center area provide an additional variable by which breeders and pathologists can estimate host plant resistance and virulence of $S$. homoeocarpa isolates. Both genotypes and isolates showed differences in the number of infection centers and infection center area (Table 3). Statistical groupings of number of infection centers associated with isolate treatments differed greatly across the two rating dates in 2012 (Fig. 5). An explanation for this change in statistical grouping between the two rating dates could be that the most virulent $S$. homoeocarpa isolates caused infection centers that coalesced together more rapidly resulting in fewer but larger infection centers at the second rating, especially for dollar spot susceptible seashore paspalum genotypes. Disease pressure was in general much weaker in the 2013 repetition of this study. This could be attributed to the difference in the time of year each repetition was inoculated (Oct. 2012 and Aug. 2013) and/or differences in air temperature and precipitation during the experiments.

To our knowledge, this is the first study to examine seashore paspalum genotype by $S$. homoeocarpa isolate interactions in the field. The $\mathrm{P} 1$ isolate shows great potential for use in screening and selection of seashore paspalum lines with enhanced dollar spot resistance, because this isolate was highly virulent across all genotypes tested (Fig. 2).

\section{Literature Cited}

Allen, T.W., A. Martinez, and L.L. Burpee. 2005. Dollar spot of turfgrass. The Plant Health Instructor. DOI:10.1094/PHI-1-2005-0217-02.

Bennett, F.T. 1937. Dollar spot disease of turf and its causal organism Sclerotinia homoeocarpa $\mathrm{n}$. sp. Ann. Appl. Biol. 24:236-257.

Bonos, S.A., M.D. Casler, and W.A. Meyer. 2003. Inheritance of dollar spot resistance in creeping bentgrass. Crop Sci. 43:2189-2196.

Bonos, S.A. 2006. Heritability of dollar spot resistance in creeping bentgrass. Phytopathology 96:808-812.

Bonos, S.A. 2011. Gene action of dollar spot resistance in creeping bentgrass. Phytopathology 159:12-18.

Chakraborty, N., J. Curley, S. Warnke, M. Casler, and G. Jung. 2006a. Mapping QTL for dollar spot resistance in creeping bentgrass (Agrostis stolonifera L.). Theor. Appl. Genet. 113:14211435.

Chakraborty, N., T. Chang, M.D. Casler, and G. Jung. 2006b. Response of bentgrass cultivars to isolates representing 10 vegetative compatibility groups. Crop Sci. 46:1237-1244.

Chapman, G.P. and W. Peat. 1992. An introduction to the grasses (including bamboos and cereals). CAB International, Wallingford, England.

Duncan, R.R. and R.N. Carrow. 2000. Seashore paspalum: The environmental turfgrass. Wiley, Hoboken, NJ. Seashore paspalum: The environmental turfgrass. Wiley, Hoboken, NJ.

Flor, N.C., P. Munoz, P. Harmon, and K. Kenworthy. 2013. Response of seashore paspalum genotypes to dollar spot disease. Intl. Turfgrass Soc. Res. J. 12:119-126.

Giordano, P.R., T.A. Nikolai, R. Hammerschmidt, and J.M. Vargas. 2012. Timing and frequency effects of lightweight rolling on dollar spot disease in creeping bentgrass putting greens. Crop Sci. 52:1371-1378.

Goodman, D.M. and L.L. Burpee. 1991. Biological control of dollar spot disease of creeping bentgrass. Phytopathology 81:1438-1446.

Honig, J.A., C. Kubik, M. Majewski, C. Poulsen, E. Weibel, K. Amundsen, and S.A. Bonos. 2014. A PCR-based linkage map of Agrostis stolonifera and identification of QTL markers for dollar spot resistance. Mol. Breed. 34:185203.

Horvath, B. and J. Vargas, Jr. 2005. Analysis of dollar spot disease severity using digital image analysis. Intl. Turfgrass Soc. Res. J. 10:196201.

Liberti, D., J.A. Rollins, and P.F. Harmon. 2012. Evidence for morphological, vegetative, genetic, and mating-type diversity in Sclerotinia homoeocarpa. Phytopathology 102:506-518.

Morris, K.N. 2005. 2003 National bentgrass testFairway/Tee test. 2004 data, Progress report NTEP No. 05-01. USDA-ARS, Beltsville, MD

Morton, J.F. 1973. Salt-tolerant silt grass (Paspalum vaginatum $\mathrm{Sw}$.). Proc. FL State Hort. Soc. 86:482-490.

Oliveira, J.A., E. Novo Uzal, F. Pomar, S.S. Bughrara, and E. Afif. 2010. Agromorphological characterization and dollar spot fungus susceptibility in accessions of common bent (Agrostis capillaris L.) collected in northern Spain. Span. J. Agr. Res. 8:56-66.

Powell, J. and J. Vargas, Jr. 2001. Vegetative compatibility and seasonal variation among isolates of Sclerotinia homoeocarpa. Plant Dis. 85:377-381.

Putman, A.I., L.P. Tredway, and I. Carbone. 2015. Characterization and distribution of matingtype genes of the turfgrass pathogen Sclerotinia homoeocarpa on a global scale. Fungal Genet. Biol. 81:25-40.

Raymer, P., S. Braman, L. Burpee, R. Carrow, Z. Chen, and T. Murphy. 2008. Seashore paspalum: Breeding a turfgrass for the future. Green Section Record 46(1):22-26.

Rotter, D., E. Merewitz, B. Huang, and F.C. Belanger. 2011. Chromosomal regions associated with dollar spot resistance in colonial bentgrass. Plant Breed. 131:193-197.

Shaner, G. and R.E. Finney. 1977. The effect of nitrogen fertilization on the expression of slowmildewing resistance in Knox wheat. Phytopathology 67:1051-1056.

Viji, G., W. Uddin, N. O'Neill, S. Mischke, and J. Saunders. 2004. Genetic diversity of Sclerotinia homoeocarpa isolates from turfgrasses from various regions in North America. Plant Dis. 88:1269-1276.

Vincelli, P., J.C. Doney, and A.J. Powell. 1997. Variation among creeping bentgrass cultivars in recovery from epidemics of dollar spot. Plant Dis. 81:99-102.

Walsh, B., S.S. Ikeda, and G.J. Boland. 1999. Biology and management of dollar spot (Sclerotinia homoeocarpa): An important disease of turfgrass. HortScience 34:13-21. 